\title{
Usos del pasado y guerra de las memorias en la Venezuela de la "Segunda Independencia"
}

\author{
Frédérique Langue \\ Mascipo-CNRS, París, Francia. Email : flangue@ehess.fr
}

\begin{abstract}
Resumen : Desde la Revolución de Independencia, el relato histórico ha ido acompañando el devenir político de Venezuela, por desempeñar un papel fundamental en la elaboración del mito unificador de la nación. Oficializado en las últimas décadas del siglo XIX, el culto a Bolívar ha sido el punto de partida de una historia oficial que, hoy en día, se asienta en una instrumentalización propia del pasado nacional. El presente ensayo intenta poner de relieve esta peculiar conformación de las memorias en su expression más reciente así como los retos que conlleva, y analizar la acérrima lucha por la escritura de la historia que se está dando hoy día en la República Bolivariana.
\end{abstract}

Palabras clave: Venezuela, historia oficial, revolución, memoria, Chávez (Hugo), Independencia

\section{Uses of the past and war abot the memories in the Venezuela of the "Second Independence"}

\begin{abstract}
Since the Revolution of Independence, the historical account has been accompanying the political evolution of Venezuela, since this plays a key role in developing the unifying myth of the nation. Formalized in an oficial way in the last decades of the nineteenth century, the cult of Bolívar's figure has been the starting point of an official history that today relies on an appropiated instrumentalization of the national past. This paper attempts to highlight this particular conformation of recent memories and its major issues, and to analyze the fierce struggle for the writing of history that is occuring now in the Bolivarian Republic.
\end{abstract}

Key words: Venezuela, official history, revolution, memory, Chavez (Hugo), Independence

\section{Usages du passé et guerre des mémoires dans le Venezuela de la "deuxième Indépendance”}

Résumé: Depuis la révolution d’Indépendance, le récit historique a accompagné le devenir politique du Venezuela, jouant de la sorte un rôle fondamental dans l'élaboration d'un mythe unificateur de la nation. Officialisé dans les dernières décennies du XIX ${ }^{\mathrm{e}}$ siècle, le culte à Bolívar a constitué le point de départ d'une histoire officielle qui se fonde désormais sur l'instrumentalisation du passé national. Cet essai vise à mettre en évidence la montée particulière des mémoires dans leurs expressions les plus récentes ainsi que les enjeux qu'elle comporte, et à analyser la confrontation sans merci qui se livre aujourd'hui dans la 
République bolivarienne sur le terrain de de l’écriture de l'histoire.

Mots clés: Venezuela, histoire officielle, révolution, mémoire, Chavez (Hugo), Indépendance

\section{Usos do Passado e Guerra de Memórias em "segunda independência” Venezuela}

Resumo: Desde a Revolução da Independência, o relato histórico tem acompanhado o futuro político da Venezuela, a desempenhar um papel fundamental no desenvolvimento do mito unificador da nação. Formalizada de forma oficial, nas últimas décadas do século XIX, o culto da figura de Bolívar tem sido o ponto de partida de uma história oficial que hoje conta com uma autoinstrumentalização do passado nacional. Este trabalho pretende destacar esta conformação particular de memórias recentes e seus principais problemas, e analisar a luta feroz para a escrita da história que está ocorrendo agora na República Bolivariana.

Palavras-chave: Venezuela, a história oficial, Revolução, memória, Chávez (Hugo), Independência.

El contexto de los Bicentenarios se presta, como se pudo comprobar a ciencia cierta, a muchas reconsideraciones históricas e incluso a la reescritura de capítulos enteros de las llamadas historias nacionales. En el caso de Venezuela, cuya Revolución Bolivariana se ha convertido en un tema mediático y mediatizado (con todas las consecuencias y falseamientos que conlleva esta situación), la polarización de las opiniones públicas tanto dentro como fuera del país no se ha reducido mayormente. Sigue vigente un ofensivo discurso anti-imperialista de alcance continental, a los diez años de la llegada al poder de su líder carismático. En la perspectiva de la historia de las representaciones y sensibilidades, no podemos sino subrayar el hecho de que ya no está operando la "seducción" que imperó en los inicios de la carrera política de Hugo Chávez (Torre 2000; Langue 2002). Ya no se alude en efecto al mago de las emociones ni mucho menos a los ángeles rebeldes que abrieron nuevas sendas políticas en el inicio de los años noventa. Desde que se dejó de abogar por la "Revolución pacífica y democrática” y se afirmó que la Revolución está “armada”, que uno está “a favor" o "en contra" sin que medie ninguna postura alternativa, se han venido imponiendo formas discursivas o más concretas de ejercicio de la violencia a diario (Zago, 1988; Uzcátegui, 1999).

Cuestionado desde el interior, por los ex compañeros de siempre, militares retirados como el general y exministro Raúl Baduel ${ }^{1}$ o consagrados ideólogos de la Revolución como Heinz Dieterich, pasando por los universitarios como la politóloga Margarita López Maya, los partidos aliados dentro de Patria para Todos, y hasta el mismo partido "único" de gobierno (PSUV, Partido Socialista Unificado de Venezuela), el fenómeno político-mediático bolivariano ha sido objeto de diversas interpretaciones, 
tanto en una perspectiva histórica como socio-política. Ambas apuntan a que se le considere al proyecto bolivariano/oficialista no en su dimensión propiamente revolucionaria y alternativa, con claros visos sociales sino en su dimensión personalista, como régimen "concentrador de poder y contradictorio”, cuya expresión más contundente ha sido el vuelco hacia el "Socialismo del siglo XXI". Hasta se ha tachado de "modelo estatista, crecientemente intolerante y autoritario”, en la línea de regímenes anteriores, fundamentalmente de la primera mitad del siglo XX (centralizados y autoritarios como el régimen de Juan Vicente Gómez (1908-1935), que la historia patria tiende a relacionar con la gesta militar de la Independencia) y en todo caso del presidencialismo propio de la $\mathrm{IV}^{\mathrm{a}}$ y de la $\mathrm{V}^{\mathrm{a}}$ República venezolana (López Maya, Lander, 2006: 43-56;; Pino Iturrieta, 2010; Langue, 2002; Guerra, 2008).

No se trata aquí de analizar formas solapadas o más obvias del ejercicio de la violencia política y de la imposición de sus juicios de valores o el papel decisivo de los aparatos ideológicos o represivos de Estado para retomar la diferenciación establecida por L. Althusser, muy sugerente en un contexto de extremada polarización política con visos revolucionarios, sino de analizar algunas manifestaciones discursivas de la misma. Se trata en especial de considerar las modalidades de escritura de la historia nacional, por ser la historia un relato en primer término, o sea de poner de relieve los usos políticos del pasado en la historia reciente de Venezuela y particularmente la imposición de una memoria histórica a través del "culto a Bolívar” y de su liturgia republicana. Hay que recordar que desde fines del año 1998, tanto las prácticas políticas nacionales como el imaginario afín han ido experimentando cambios señeros aunque no todos impredecibles si nos ubicamos precisamente en la larga duración de la historia política nacional - y más aún en la perspectiva de la historia de las ideas y de las representaciones sociales. Hay que recordar que la historia reciente de Venezuela había sido hasta aquella fecha, la de una democracia consensuada (el consenso de las élites dentro del bipartidismo protagonizado por Acción Democrática y COPEI) que contrastaba con el resto del continente, gobernado por regímenes autoritarios y hasta dictaduras (el denominado “excepcionalismo venezolano”) (Ramos Jiménez, 2002). Sin embargo, la llegada al poder de un líder carismático (elecciones presidenciales de diciembre de 1998) y la consiguiente denuncia del régimen partidista instaurado a raíz de la caída de la dictablanda de Pérez Jiménez y más precisamente del pacto de Punto Fijo (1958) no influyó de inmediato en las prácticas discursivas o patrimoniales que señalamos, al contrario, ya que se abogó por una democracia participativa y unos equilibrios tanto en lo social como en lo político y económico.

De cierto modo, la gobernabilidad criolla se había venido desarrollando hasta la década de los noventa en el marco de una "paz violenta", para retomar la caracterización de David. R. Mares acerca de las relaciones interestatales a escala continental, antes de que se radicalizarán discurso, lenguaje y prácticas a instancias y a favor de un líder identificado por sus seguidores como el Bolívar del siglo XXI. Fue a partir del año 2002, y más 
particularmente a raíz de los llamados “sucesos de abril” (intento de golpe de Estado en contra de H. Chávez) cuando el imaginario bolivariano se radicalizó. Con este fin, se apoyó en un proceso político atípico aunque también inscrito en la larga duración de las prácticas políticas e históricas nacionales, para desembocar en la inclusión y más adelante la reinvención del culto a Bolívar, esto en el marco de una historia oficial abiertamente promovida por el Estado venezolano y de la consiguiente guerra de las memorias que desató entre los historiadores de oficio (Mares, 2001; Langue, 2009a: 95-136).

\section{Un imaginario político radicalizado, entre democracia plebiscitaria y pretorianismo recurrente}

Cuando se radicalizó el discurso de la Revolución Bolivariana en el transcurso del año 2002, se sistematizó en efecto el recurso a la figura libertadora de Bolívar, al paso de una cronología que resulta imprescindible retomar aquí, aunque sea a breves pinceladas, en la medida en que sustenta y propicia a la vez un lenguaje ofensivo y hasta un discurso de la violencia, desde ambos bandos y hasta en lo que a escritura de la historia se refiere. No se trata sin embargo de analizar la acción discursiva en un plano político, la semiología propia de cada bando, sino la intención y los medios propuestos en un contexto revolucionario o reivindicado como tal. El acto de lenguaje apunta aquí a influir en el entorno por medio de las palabras; busca informar, pedir, convencer, prometer, inducir a determinadas formas de (re)acción y de transformación de las representaciones alternas. En el caso de H. Chávez, y más allá de su contenido semántico, el mensaje es voluntarista, no suele aconsejar sino decretar, refutar, condenar, rectificar, mofar, ironizar, y emocionar a la vez. Corre parejas con la violencia de las imágenes que hace que no se puede entender cabalmente la escritura de la historia y la historia de las ideas en la Venezuela de hoy sin tomar en cuenta la historia visual de la misma, dentro del proceso de mediatización que la caracteriza desde la llegada al escenario mediático del Comandante (recordamos la rendición de los cabecillas del intento de golpe de Estado del 4 febrero de 1992 y el famoso "por ahora” en la declaración televisada, por lo cual el teniente coronel renunció provisionalmente a llegar al poder).

Se ha subrayado en varias oportunidades el hecho de que el discurso de Hugo Chávez resultó más ser violento que los actos mismos, aunque fueran protagonizados por lo que se ha llamado por ejemplo los "círculos violentos” (Guardia Rolando y Olivieri, 2003: 85-107; Guardia Rolando y Guerrero Álvarez, 2010: 305-321). Pero de igual manera podemos encontrar expresiones partidarias violentas durante manifestaciones callejeras - especialmente en contra de las marchas opositoras cuando de violencia física se trata - o en ataques a los medios de comunicación "escuálidos", financiados por el "imperio", ataques que se han ido multiplicando desde el año 2004 junto a la promulgación de la ley Resorte o Ley de Responsabilidad Social en Radio y Televisión, el 7 de diciembre de 2004, y la 
promulgación en diciembre de 2010 de otra destinada a restringir la libertad de expresión y de prensa promoviendo una auto-censura, la Ley de Responsabilidad Social en Radio, Televisión y Medios Electrónicos² . De tal forma que, más que oponer palabra y acción, conviene considerar aquí que la palabra en cuanto forma de actuar — son los "actos de lenguaje" evidenciados por J. Austin-, de comunicar y hasta de fomentar la acción (Kerbrat-Orecchioni, 2008; Searl, 1972). En este sentido, no carece de interés recordar que J. Austin profundizó este tipo de análisis hasta definir "actos de lenguaje", lo que contribuye en evidenciar los efectos del discurso sur la subjetividad del momento. De ahí la importancia que vienen cobrado los mecanismos del discurso violento en sus distintos niveles (del "pueblo a su líder carismático) junto a las modalidades de su enunciación. Comunicar es parte de relaciones de poder y de dominación política, expresión de una voluntad eficiente de cambiar el mundo mediante el "poder" algo mágico y los efectos simbólicos llevados por las palabras mismas (Austin, 1991; Bourdieu, 1982; Eribon, 1982).

De ahí la insoslayable pregunta acerca del papel desempeñado por el lenguaje en la polémica que da al traste de forma sistemática con el diálogo propio de la democracia representativa y propicia el uso - aunque en primer lugar en su vertiente discursiva - de la violencia. ¿Cuáles son los elementos fundadores de esta violencia en el discurso político, ya sea del líder, o bien de sus seguidores o también de sus opositores ¿Cómo evaluar la aprensión que de las formas de violencia ajenas tienen unos y otros, dependiendo del "bando" a que pertenecen, "ni-ni" (ni Chávez, ni oposición) incluidos? Hay que recordar, además del trauma que de la violencia se deriva, que la violencia no se deja describir: las violencias siempre son singulares a la par que se ubican en determinado contexto (enfrentamiento, armado o no, masacre, agresión de cualquier tipo etc.), se insertan en una tipología precisa (violencia política precisamente, de género etc.) o van ligadas a estructuras o instituciones a carácter violento/represivo (caso de la larga revuelta carcelaria del Rodeo en junio de 2011 en Venezuela) ${ }^{3}$.

Contextualizar el acontecer violento, la "recepción” del mismo de acuerdo con la conceptualización de P. Laborie, en la perspectiva de una historia de las representaciones y sensibilidades aplicada al tiempo presente, permite diferenciar las formas y los niveles de violencia, las escalas de la misma, el papel o mejor dicho el manejo instrumental del desencanto, del resentimiento y de la inversión de valores en que se origina (i.e. el regreso del sector militar bajo lemas igualitaristas y revolucionarios), a través de una venganza restauradora de la dignidad de los ex vencidos y oprimidos. El contexto venezolano no se presta en efecto a una interpretación en términos de represión, o de legitimidad de una respuesta violenta como es el caso para los países del Cono Sur en la década de los setenta, con el añadido de otro factor desconocido en el caso venezolano, que es el terrorismo de Estado. Aunque la relación entre violencia y subversión que funcionan como "auténticos mitos políticos" como lo subraya a ciencia cierta Marina Franco para Argentina, sí está presente a través del tema del complot (Franco, 2012: 324). El sentido de la lectura que Hugo Chávez 
hace del pasado lejano o más reciente, nos lleva hacia la responsabilidad histórica de los dos imperios (el de antes y el de hoy), lectura respaldada por sensibilidades y hasta visiones del mundo y sus derivaciones: las emociones creadas, tales como miedo, odio, resentimiento, ligadas ocasionalmente a fenómenos de creencias o mitos - el "culto a Bolívar” ejemplificado por G. Carrera Damas - de que los procesos revolucionarios en escasas oportunidades se libraron. Dicho de otra forma, la temporalidad del acontecer no sólo sobrepasa con creces la temporalidad de los hechos referidos, sino que percepciones y sensibilidades ligadas al contexto histórico y social, alteridades múltiples, y las mismas representaciones históricas influyen en la aprensión de los hechos, el acontecer genera memoria dentro de las relaciones sociales y políticas, recuerdo no siempre proporcional a su escala o impactos iniciales (de ahí la referencia a las sensibilidades y no sólo a las emociones que sólo son una resultante puntual, muy circunscrita en el tiempo), se construye/interpreta de forme permanente y hasta encierra una visión del futuro (Laborie, 2001; Farge, 2002: 69-78 ; Carrera Damas, 1989; Capriles, 2008: 36; Salas de Lecuna, 1987 y 2005: 241-263: Arenas y Gómez Calcaño, 2004; Ferro, 2007; Torres, 2009: 156-158).

Ahora bien, dentro de las estrategias políticas ideadas por el líder y su gobierno, figura un instrumento fundamental, del cual el historiador no puede hacer caso omiso a la hora de analizar las relaciones entre historia, violencia y política: las modalidades de escritura de la historia, dicho de otra forma, la historia oficial forjada por y desde el poder político, su retórica propia, el papel del discurso histórico o historicizante. Sus recursos se derivan de una mitología bolivariana que se sustenta en una fascinación colectiva por la figura del insurgente/“alzao”/rebelde convertida no sólo en elemento clave del imaginario popular y parte de una memoria colectiva sino también en argumento político (culto cívico) como tempranamente lo pusieron de relieve Y. Salas o G. Carrera Damas y, por ende, de la instrumentalización del pasado de que ni se eximen en muchos casos regímenes democráticos. No se trata por lo tanto de caer en una suerte de "violentología” tal como se ha ejemplificado en el caso colombiano, tampoco en una abstracción interpretativa e ideologizada. De ahí la imprescindible contextualización que privilegiamos en este estudio, y el convencimiento de que también puede ser arma el mencionado discurso historicizante en cuanto forma superior ya que elaborada y orientada del acto de lenguaje, incluso en la vertiente emocional constantemente manejada por el presidente Chávez (Carrera Damas, 1989; Salas de Lecuna, 1987; Torres, 2009: 160; Pratt, 2011).

El propósito político obvio de los discursos presidenciales, aunque estrechamente vinculado a un variopinto sustrato ideológico, no excluye sin embargo la presencia de formas duraderas de subjetividad entre los "receptores". De ahí el interés de las prácticas discursivas relacionadas con el "proceso"4 y su líder carismático (Guilhaumou, Maldidier y Prost, 1974; Narvaja de Arnoux, 2008), en la medida en que se derivan de representaciones sociales y políticas ubicadas en el tiempo largo. Asimismo se relacionan con un imaginario criollo constantemente reforzado o reelaborado 
en el nivel simbólico mediante lemas tajantes (últimamente: "patria, socialismo o muerte”, según el modelo cubano, lema oportunamente modificado a instancia de Raúl Castro después de cambiarse el lema en la propia Cuba y luego de la enfermedad de H. Chávez en el verano 2011: sólo queda en adelante «Patria socialista y victoria, venceremos»). También habría que mencionar en ese aspecto las ceremonias, fechas y lugares de memoria que tienden a reforzar el culto cívico-militar, siendo el ejemplo más llamativo el episodio teatralizado de la exhumación de los restos del Libertador en julio de 2010 "retocado" aunque en perjuicio de la interpretación presidencial en julio del año siguiente, y el regreso del héroe al Panteón nacional, el desfile "cívico-militar" en la terminología oficial del Bicentenario, en el Paseo de los Próceres el 5 de julio de 2011. La culminación de esa fase del culto cívico con las celebraciones del Bicentenario y el estratégico y oportuno regreso de Cuba del líder héroe, en una suerte de "Aclamación” que no deja de recordar otros períodos de la historia patria (el régimen positivista del "Ilustre Americano", Antonio Guzmán Blanco, 1870-1788, si incluimos el gobierno de unos testaferros) no debe ocultar la inclusión de aconteceres violentos en el calendario revolucionario, y la reconversión de éstos mediante otra cualificación: "insurrección patriótica”, "insurrección militar", "rebelión militar" en el caso del intento de golpe de Estado protagonizado por Hugo Chávez el 4 de febrero de 1992, celebrado desde 2008 como el Día de la Dignidad Nacional, y Día de la Dignidad venezolana en Cuba, equiparando de esta forma ambos procesos revolucionarios (Peñaloza, $2011)^{5}$.

Esta etapa conforta sin lugar a dudas la radicalización del discurso de la Revolución, o mejor dicho del denominado Socialismo del siglo XIX. De cierta forma, pone término a un período de "paros cívicos” y huelgas generales, vías privilegiadas de la contienda política hasta esa fecha, protagonizadas por opositores tanto civiles como militares si recordamos tan sólo los "sucesos de abril" o sea el controvertido intento de golpe de Estado en contra de H. Chávez en 2002, o la rebeldía de los auto-nombrados militares democráticos en el año 2004. En 2007, se crea el Partido Socialista Unificado de Venezuela (PSUV) y se va acentuando la extrema polarización de las opciones políticas y de la opinión pública junto al desvelamiento del proyecto político e ideológico —el llamado Socialismo del siglo XXI-. La violencia política, presente tanto en el discurso de un Estado centralizado como en una oposición en busca de un líder, se plasmó en reiterados enfrentamientos ocasionales, con motivo de protestas estudiantiles o consecutivas al cierre de canales de televisión etc. ${ }^{6}$.

Esta notable inflexión ideológica coincidió además con otra fecha de lo más simbólica y con una fuerte carga social, la del décimo aniversario del Caracazo de febrero de 1989, revuelta popular que dio inicio a una concientización social de los jóvenes oficiales, de acuerdo con el testimonio del propio Comandante. Se llegó a superponer al aniversario de la fallida "rebelión de los ángeles" o sea el golpe de Estado protagonizado por $\mathrm{H}$. Chávez con fecha del 4 de febrero de 1992 (Zago, 1998). De tal forma que en el registro conmemorativo de la República Bolivariana, el mes de febre- 
ro se ha convertido en uno de los hitos de un calendario revolucionario amante de las metáforas militares. La controvertida adopción por vía de referéndum en febrero de 2009 de una enmienda constitucional que autorizó el desempeño de un cargo electivo sin limitación de mandato en el tiempo (mandato presidencial incluido), es parte de esa singular estrategia de conquista y de transformación del poder que sólo el análisis del imaginario político local y de las prácticas políticas criollas en el tiempo largo permite aclarar, y especialmente por lo que toca a uno de sus componentes, las relaciones civiles-militares.

El plebiscito de febrero de 2009 resulta en efecto simbólico en varios aspectos, habida cuenta de las contrastadas relaciones que se vienen tejiendo en esa oportunidad entre memoria criolla, historia nacional y escritura de la misma, promovidas en adelante de un modo oficial. No se reduce en efecto a una maniqueísta contraposición entre una democracia electoral/formal no exclusiva de un régimen autoritario y la otrora democracia representativa. Lo atípico de la configuración política de los siglos XX y XXI, tanto en lo que respecta al líder como al proceso, justifica la caracterización en términos de laboratorio de la política venezolana o “experimento bolivariano” que no encaja verdaderamente en las categorías trilladas del análisis político (Ramos Jiménez, 2009). Ahora bien, la reivindicación de la gesta de los libertadores del continente latinoamericano, gesta de notable impronta mesiánica, hace de H. Chávez el Bolívar de hoy, el nuevo constructor de la Patria Grande, y la encarnación del "destino superior de los pueblos latinoamericanos” (expresión acuñada por H. Dieterich, 2004). Semejantes referencias sin embargo no pueden entenderse de no tomar en cuenta unas prácticas políticas arraigadas en el culto bolivariano y en un personalismo político. Además, no pocos elementos de estas dos realidades apuntan sin lugar a dudas al discurso de cuño populista (alusiones constantes a un líder carismático, retórica antipolítica ante el "fracaso" de los partidos políticos, ausencia de mediación en la relación establecida con el pueblo, etc.), junto a las movilizadoras y consensuales denuncias antiimperialistas (Dieterich, 2004; Jácome, 2008).

Desde el punto de vista de la historia de las ideas, hay que recordar que los partidos políticos modernos se remontan en el caso venezolano a la década de los cuarenta (Acción democrática al año 1941 y el partido social-cristiano COPEI a 1946). Hasta esa década clave, la persistencia del fenómeno caudillista incidió sobremanera en la vida política criolla. El acceso a la modernidad en términos de representatividad democrática encerró sin embargo varias paradojas. Acción democrática (AD) fue fundada por antiguos miembros de organizaciones marxistas, especialmente del Partido comunista (PCV, 1929). Esta configuración anclada en un pasado de lucha violenta y clandestinidad difiere por tanto de la situación que se observó en el Brasil de Getulio Vargas o en la Argentina de Juan Domingo Perón. Hay que recordar además que fue uno de sus fundadores y mayores inspiradores en lo ideológico, Rómulo Betancourt, presidente de la República de 1959 a 1964, quien llegó a ser para sus conciudadanos el "padre de la democracia venezolana” (Langue, 2009b). La segunda paradoja, algo 
olvidada fuera del ámbito académico venezolano, tiene que ver con la "Revolución de octubre” (1945) que llevó a AD al poder. Este golpe de Estado desterró a la élite gobernante formada durante el régimen del "tirano liberal” Juan Vicente Gómez (1908-1935). Tal fue el punto de partida de la simbiosis civiles-militares, característica de un consenso que influyó de forma duradera en los procesos institucionales y políticos del país: desde el derrocamiento en 1948 del presidente electo, Rómulo Gallegos, hasta la dictadura de Marcos Pérez Jiménez (1952-1958), la caída de éste el 23 de enero de 1958 y el pacto de Punto Fijo, fundador de una democracia ejemplar en el contexto continental a lo largo de cuatro décadas (Langue, 2002: 94 y ss.; Gómez, 1994).

Estas cuatro décadas de democracia representativa y hasta de "Estado mágico" fundada en la alternancia de los partidos social-demócrata (AD) y social-cristiano (Copei) en el poder, respaldada por la prosperidad petrolera, considerado con sobrada razón como un consenso de las élites (alto mando militar incluido) y un "sistema populista de conciliación nacional", contrastan con la situación los regímenes autoritarios o dictaduras militares de los países vecinos, incluso durante la fase de lucha armada de principios de los años sesenta (Coronil, 2002: 77; Rey, 1991). En ese sentido, y para comprender el papel del sector militar hasta hoy, conviene obviar el concepto de militarismo en provecho del de pretorianismo, en cuanto influencia abusiva (y no absoluta sobre el gobierno y la sociedad) o utilización de la fuerza simbólica o real de parte de las fuerzas armadas. La tendencia pretoriana, reforzada y encauzada a la vez por la modernización e institucionalización del ejército durante el gobierno del tirano liberal Juan Vicente Gómez seguiría existiendo de forma latente hasta el día de hoy. Los intentos de golpe de Estado de 1992 y 2002 (intento de golpe de Estado para derrocar a H. Chávez), no serían sino la "expresión de ese pretorianismo recurrente del siglo XX” (Irwin y Langue, 2004; Irwin, 2010: 743-760; Buttó, 2010: 783-800; Caballero, 1998: 165-167; Caballero, 1993: 203 y ss.).

En esta tendencia de largo alcance, suerte de conspiración permanente en los términos de D. Irwin, se ubica precisamente el movimiento bolivariano, logia militar clandestina en sus inicios, fundada simbólicamente el año del bicentenario del natalicio del Libertador (1983) antes de desembocar en 1997 en el partido Movimiento V ${ }^{\mathrm{a}}$ República, en vísperas precisamente de las elecciones presidenciales y en enero de 2007, en el Partido Socialista Unificado de Venezuela (PSUV), que no logró sin embargo incluir a todas las fuerzas de izquierda (PCV). Bajo la influencia del sociólogo argentino Norberto Ceresole, propagandista de la relación caudillo-ejército-pueblo —es autor en 2000 de Caudillo, ejército, pueblo. La Venezuela del Comandante Chávez - y antiguo consejero de las dictaduras del Cono Sur, la Constitución bolivariana de 1999, relativiza el control civil de las décadas anteriores e insiste en la "responsabilidad conjunta del Estado y de la sociedad" bajo un mando único que le corresponde al presidente. Este cambio se va a plasmar en los siguientes años en la creación de las milicias bolivarianas y de la reserva ante el riesgo (sic) de guerra 
asimétrica con Estados Unidos (Castillo, Irwin y Langue, 2009; Aponte Blank, 2009).

\section{Usos bolivarianos del pasado: los paradigmas de la historia oficial}

Fue en las postrimerías del siglo XIX cuando el Libertador Simón Bolívar se convirtió de forma definitiva en el referente histórico de los gobernantes venezolanos y la historia nacional en una "política de Estado" (Almarza, 2011). Después del regreso de las cenizas del héroe en 1842 Bolívar murió en 1830 en Santa Marta, Colombia_- , los presidentes de la República, particularmente el positivista Antonio Guzmán Blanco (18701888), se afanaron en promover ese culto cívico celebrado desde el Panteón Nacional (Langue, 2004 y 2009c: 215-230; Rojas, 2011: 185 y ss.; Pino Iturrieta, 2003: 17 y ss.). El culto al héroe de la gesta independentista se inició un 28 de octubre de 1876 — día de San Simón- día en que los restos del Libertador, identificados previamente por el doctor José María Vargas (Presidente de la República de 1835 a 1839) fueron llevados al Panteón Nacional. En los siguientes años, el culto cívico incluyó tanto la exhibición de reliquias del Libertador como ceremonias oficiales encaminadas en fundar la liturgia cívica: el paseo triunfal con motivo de las "Fiestas de la Paz" (28 de octubre de 1872), la inauguración de una estatua ecuestre en Caracas (7 de noviembre de 1874), el traslado de sus cenizas al Panteón Nacional (28 de octubre de 1876), y la celebración el Centenario de su nacimiento (1883). Sin embargo, el imaginario redentor propio de la gesta bolivariana, la de ayer y la de hoy, no aparece claramente sino hasta la llamada Revolución de octubre (1945), punto de partida de una evolución que culmina con la denominación oficial de la República, bolivariana (Constitución de 1999). Durante el guzmanato se impone la figura más bien conservadora del Libertador, de un poder concentrado y centralizado que participa del personalismo político encarnado en ese momento por el Ilustre Americano Antonio Guzmán Blanco (González, 2007; Pino Iturrieta, 2007; Arenas y Gómez Calcaño, 2000).

El culto a Bolívar, culto por y para el pueblo de acuerdo con Germán Carrera Damas lo reinventa de cierto modo la Revolución Bolivariana: se impone la imagen del revolucionario en lo social, y propagandistas de la Revolución hasta hacen del mantuano ${ }^{7}$ Bolívar un zambo, en todo caso un mestizo de piel oscura (Pino Iturrieta, 2007: 87-88, 93-105; Langue, 2011). La muy redentora Revolución - hay que salvar al mundo de acuerdo con H. Chávez- le añade en efecto la referencia al árbol de las tres raíces (Simón Bolívar, Simón Rodríguez, Ezequiel Zamora, "general del pueblo soberano" del siglo XIX) celebrado por el Movimiento Bolivariano desde su creación en 1783, año del Bicentenario del natalicio del Libertador. Ahora bien, la máxima expresión de la instrumentalización de la historia por el poder quizás radique en la transformación de los símbolos patrios (2006), junto a las celebraciones reforzadas por desfiles militares que menciona- 
mos anteriormente (intento de golpe de Estado de 1992) ${ }^{8}$. El culto bolivariano ideado por la República bolivariana se funda además en símbolos de alcance continental. Tal es el caso de la vengadora espada del Libertador, propiedad de la Nación desde 1889, recordada en los textos fundacionales del Movimiento bolivariano, reivindicada por movimientos guerrilleros (el M-19 colombiano en los años 70) y movimientos izquierdistas más recientes y hasta alter-mundialistas, "paseada” no sólo por el país sino por el continente por los adalides de la "revolución” y regalada de forma sistemática a los jefes de Estado amigos de la Revolución (Pino Iturrieta, 2003; Gómez, 2005: 179-203; Carrera Damas, 2001; ANH, comunicado 2006).

No hay que olvidar sin embargo que la referencia al "divino Bolívar” (E. Pino Iturrieta) no se puede desligar de otro referente mayor de la historia política nacional, un personalismo político que se origina en la teoría en la necesidad de un gobernante fuerte en términos de Laureano Vallenilla Lanz, intelectual orgánico del gomecismo para retomar la categoría gramsciana. El parecido que se ha establecido entre el itinerario y la actuación presidenciales con el de José Tadeo Monagas, presidente en los años 1847-1858, pone de relieve la permanencia en la historia criolla de esos "hombres de armas " y hasta de "caudillos” quienes desconfían de los partidos y se rodean exclusivamente de un cenáculo familiar, llegando a controlar el aparato de Estado. Tal fue la primera expresión verdadera del personalismo venezolano. De ahí el hecho de la caracterización adelantada por G. Carrera Damas, de un "bolivarianismo-militarismo” punto de partida del manejo a la vez discrecional y autoritario del culto heroico en su versión actual. En ese rubro encajaría asimismo el recuerdo - pasado por alto por los turiferarios de la historia oficial - de la dictadura comisoria encabezada por Bolívar en 1828 y de la República liberal autocrática ideada por el Libertador, junto a la exaltación del heroísmo tradicionalmente atribuido al hombre de armas. El carácter fragmentario de las referencias a Bolívar y la descontextualización de las mismas son parte de esa peculiar instrumentalización de la historia encaminada a forjar una nueva historia oficial y propiciar una pseudo-conciencia histórica en respaldo de un proyecto político, mientras la comprobación de los hechos por historiadores de oficio tienden a rebatir la versión oficial (cf. la misma averiguación de los restos del Libertador decretada por el presidente) (Pino Iturrieta, 2007; Carrera Damas, 2001 y 2007: 203-210; Langue, 2011; Lynch, 2007; Straka, 2009: 84-93; Irwin y Buttó, 2006; Hernández, 2010).

Otro punto clave de la conformación de esta nueva historia oficial: el papel del jefe de gobierno, ubicado de hecho en una larga tradición presidencialista criolla. En este sentido, el presidente Chávez es el gobernante que mayor poder ha disfrutado en la historia del país desde el régimen del Benemérito Juan Vicente Gómez (1908-1935), circunstancia que encaja en casi todas las teorías políticas que se reivindicado el período de Independencia. En la perspectiva de la historia de las ideas, el gobernante fuerte se ha convertido en concepto hegemónico fundado en la idea directriz de una presidencia vitalicia y de un poder moral cuyo depositario fue 
precisamente Simón Bolívar después del Congreso de Angostura (1819), y que aparece debidamente mencionado en la Constitución de la República de Bolivia (1826). En la actual teleología bolivariana, de acuerdo con el presidente Chávez, no hay ruptura entre la Revolución de hoy y la mítica Revolución de Independencia ((Pino Iturrieta, 2003b; Plaza, 2001: 7-24; Langue, 2009c y d).

El último "resorte" que quisiéramos resaltar aquí tiene que ver con la figura del buen revolucionario, muy parecido al "hombre nuevo" guevarista aunque analizado in situ por el escritor, periodista y diplomático Carlos Rangel. Desde 1976, año de publicación de Del buen salvaje al buen revolucionario. Mitos y realidades de América Latina, el autor puso de relieve las derivas autoritarias y hasta dictatoriales de las revueltas de inspiración marxista en el continente, y especialmente esa singular mezcla de indigenismo y populismo que desemboca en el "revolucionarismo secular”, juntando el mito del buen salvaje y el del buen revolucionario.

Ese ejercicio personal del poder en que se origina el “cesarismo populista” se expresa en términos de emociones, de sensibilidades y pasiones, lo que dificulta su inclusión en una determinada tipología política. En sus prácticas discursivas se evidencia la misión algo teleológica del Estado y más aún de su líder, encaminada hacia la formación de ciudadanos virtuosos, de que es parte integrante la refundación de la historia nacional: la Revolución de Independencia abrió en efecto "el camino hacia la liberación de Venezuela”, como lo puntualiza el número 11 (2011) del boletín del Centro Nacional de Historia, Memorias, título precedido de esta advertencia: "El pueblo es la historia” (Rangel, 2007; González Deluca, 2005: 159186,; García Larralde, 2007) ${ }^{9}$.

\section{La guerra de las memorias}

La “Historia insurgente” y “descolonización de las memorias” que acompañan en adelante la organización de los coloquios de historia (Memorias $n^{\circ} 11-2011$ ), se apoyan desde 2007 en una institución formal, el Centro Nacional de Historia. Creado por el "gobierno revolucionario de la República Bolivariana de Venezuela a través del Ministerio del Poder Popular para la Cultura”, se ubica de entrada en una confusión naturalista entre historia y memoria - Hacer memoria es hacer historia, reza el editorial del primer número de su revista/boletín, cuyo nombre reivindica de forma paradójica la diversidad de las memorias -Memorias de Venezuela-, en contradicción con el propósito ideológico reivindicado-, conjunción de la que muchos historiadores y pensadores, entre ellos Paul Ricœur, advirtieron el peligro. Tiene como “misión” explícita “ejercer la rectoría de las políticas y desarrollar las acciones y actividades del Estado venezolano en lo concerniente al conocimiento, investigación, resguardo y difusión de la historia nacional y la memoria colectiva y patrimonio histórico del pueblo, garantizando el derecho de las comunidades a participar en el enriquecimiento de los mismos”. El CNH tiene como misión garantizar 
“...la democratización de la memoria a partir de la formación, la investigación y la difusión de los procesos históricos que dan cuenta de la construcción colectiva de la Nación venezolana. Por tanto, el Centro propiciará formas de hacer llegar la historia al pueblo venezolano, impulsará la construcción de discursos históricos inclusivos [el subrayado es nuestro] en los que el pueblo se reconozca como protagonista de su devenir y propiciará la investigación participativa en función de una construcción colectiva de los saberes historiográficos”"

El CNH rechaza la concepción de la historia como "conocimiento libresco", por considerarla como "una herramienta de construcción del futuro", asimismo cuestiona "la perspectiva de una historia lineal y progresiva, cuyo sentido profundo ha sido la articulación de la sociedad venezolana al sistema capitalista mundial como designio fatal" y "se propone construir una historia que explique, describa y relate la formación de los mecanismos de dominación y de explotación, así como las formas en que los venezolanos nos hemos organizado para combatirlos y reemplazarlos por formas de convivencia más justas y libres". Se propone contemplar "todos los elementos constitutivos de la dinámica de la sociedad: lo social, lo político, lo cultural, lo económico, lo ideológico, lo cotidiano, entre otros”, apoyándose en "ejes transversales" como la "diversidad temporal, territorial, cultural, étnica, social y de género” con el fin de crear un "conocimiento histórico incluyente”, con presencia protagónica de los sectores sociales históricamente excluidos, que propicie el reconocimiento de la sociedad multiétnica y pluricultural en función de la construcción de la sociedad democrática participativa y protagónica; y la constitución del Estado de Derecho y Justicia, en libertad, igualdad y solidaridad. Una historia que, en lugar de operar como justificación ideológica, está concebida como una herramienta para la liberación”.

La referencia explícita a los héroes locales — véanse Memorias de la insurgencia, libro colectivo publicado por el Centro Nacional de Historia en 2011, que no es sino un listado profuso de los protagonistas populares de la gesta independentista - respalda sin embargo este rescate de la historia encauzada hacia la "masiva divulgación del conocimiento histórico, al objeto de robustecer la conciencia social y política de nuestra sociedad”. Un párrafo del primer editorial resulta muy ilustrativo de esta confusión entre memoria e historia, y de la instrumentalización de ésta señalada por P. Ricœur (Ricœur, 2000):

"Los Museos Bolivarianos, el Museo Nacional de Historia y la revista Memorias de Venezuela son instrumentos de esta estrategia rememorizadora. Su acción va dirigida al gran público, escolares, estudiantes, maestros, docentes, autodidactas, no para reinterpretar la historia a la medida de un proyecto político, sino para hacer una nueva política de la memoria en la que resurjan los actores y circunstancias que la historia académica redujo al olvido, y que tenga en perspectiva la construcción de una sociedad justa, equitativa e incluyente”11. 
Al fundarse en los principios rectores de la gesta bolivariana, esta "historia herramienta" abiertamente postulada inserta los hechos en una revisión mítica y mesiánica del culto fundacional. El fundamentalismo heroico así establecido según Ana Teresa Torres dio pie a iniciativas del poder político: entre diciembre 2007 y enero de 2008 se creó la comisión presidencial encargada de investigar las circunstancias exactas de la muerte de Bolívar, asesinado, habida cuenta de la convicción de H. Chávez de que el Libertador había sido asesinado por los “oligarcas venezolanos y colombianos” y por lo tanto no había muerto de tuberculosis, como lo dejaron bien claro la historia patria y la ciencia reunidas, ésta por medio del Dr. José María Vargas, primer civil presidente de Venezuela (1835-1839). Celebrada en vísperas de las elecciones parlamentarias de septiembre de 2010, esa contundente revisión de la historia nacional busca reunir (¿identificar?) al héroe de antaño con el del tiempo presente, por ser H. Chávez el “Bolívar del siglo XXI", “taumaturgo del pueblo” (E. Pino Iturrieta) cuya misión continental y hasta universal se desarrolla bajo las amenazas constante del Imperio (sic) incluso de los intentos de éste por asesinarlo. Este tema redundante del magnicidio, omnipresente en los discursos castristas y luego chavistas, forma parte de las “tradiciones inventadas” (T. Straka) y corren parejas con el tema de la "segunda Independencia, y más aún en el contexto de las conmemoraciones del Bicentenario de la "primera” (El Universal, 29 y 30 enero, 2008; Pino Iturrieta, 2003, Soriano de García Pelayo, 1996 ; Torres, 2009 : 19 y ss ; Straka, 2009 : 173 y ss ; Langue, 2009c).

Una etapa fundamental de la contienda histórica fue por lo tanto la muy mediatizada exhumación de los restos del Libertador en julio de 2010 desde el lugar de memoria por antonomasia que es el Panteón Nacional, en presencia de “expertos forenses" e “investigadores” vestidos de blanco contratados para aseverar que el Libertador no murió de tisis, sino que fue asesinado. De ahí nuevos y acérrimos debates acerca de las modalidades del culto a Bolívar y de la reinvención del héroe. Una exposición, titulada “La exhumación de los restos de Bolívar”, se organizó paralelamente en el Museo Bolivariano, completada por otra, también dedicada al mantuano Libertador bajo el título “Bolívar popular, Bolívar de verdad”. Estos eventos contaron con una amplia difusión en los medios de comunicación oficiales, y hasta del mismo presidente Chávez, por medio de su cuenta Twitter (@chavezcandanga; Rico, 2010) ${ }^{12}$. La Academia Nacional de la Historia reaccionó enseguida denunciando la “profanación de los restos de Bolívar ”. Subrayó asimismo que

“ el acto de exhumación [fue] realizado sorpresivamente, en la medianoche del 15 al 16 del presente mes (...) un espectáculo y una retórica inéditos en la historia venezolana, y que quedará para siempre inscrito en los Anales de Venezuela como el irrespeto más grave que se le haya hecho al Libertador Simón Bolívar, y con él al símbolo más genuino de la Patria ${ }^{\text {13. }}$.

“El regreso a casa del Libertador”, fue, sin embargo, el surrealista 
encabezado de la revista del Centro Nacional de Historia dedicada al episodio de la exhumación de los restos de Bolívar, Memorias de Venezuela (septiembre 2010, no. 15), con un editorial centrado nuevamente en el "intento de magnicidio contra el Libertador", afirmación asentada en una corta aunque selecta bibliografía ${ }^{14}$. No dejó de recordar en esa oportunidad el decreto promulgado el 30 de abril de 1842 por el Presidente de la República, el General José Antonio Páez, sobre el traslado de los restos del Libertador de Santa Marta a Caracas, el papel de la Comisión presidida por el Doctor Vargas, y el traslado final del sarcófago desde el panteón familiar de la Iglesia Catedral al Panteón Nacional, en otra ceremonia solemne presidida por el General Antonio Guzmán Blanco el 28 de octubre de 1876 (Pino Iturrieta, 2003 ; Straka, 2009: 173 y ss).

Hay que recordar además que, antes de que se iniciara este debate acerca de la "profanación de los restos del Libertador", más precisamente el 6 de junio de 2010, otra ceremonia muy controvertida había tenido lugar. Para que el "pueblo" pueda tener acceso a las fuentes de su historia, el gobierno decretó en efecto que se trasladaran los archivos de los próceres Simón Bolívar y Francisco de Miranda, anteriormente custodiados por la Academia Nacional de la Historia, al Archivo General de la Nación. Más que el acontecimiento y el dato en sí mismos, importan aquí los términos del debate que se encendió en esa oportunidad. En esa oportunidad, Elías Pino Iturrieta, director de la referida Academia Nacional de la Historia, institución de reconocido prestigio creada por decreto del presidente Juan Pablo Rojas Paúl en 1888, renuente a la intromisión del poder político en el quehacer de los historiadores (remitimos a la polémica protagonizada por los académicos en 2006 cuando H. Chávez decidió rectificar los llamados “símbolos patrios”), señaló el carácter político de esta medida encaminada oficialmente a "rescatar la memoria histórica de las luchas de liberación del pueblo venezolano", luchas anteriormente “...ocultadas por factores políticos contrarios al proceso revolucionario” en las palabras del director del AGN. En términos más radicales también y antes de que se iniciara la llamada "rebelión de los historiadores", el historiador G. Carrera Damas ya había denunciado la "ideología de reemplazo" que opaca una verdadera reflexión historiográfica, historia oficial ya (Pino Iturrieta, 2003b y 2007; Lombardi, 2010; Straka, 2009a: 21-60 y 2009b: 51-91 ; Langue, 2011) ${ }^{15}$.

\section{Una reflexión necesariamente inconclusa}

Esta instrumentalización de la historia y los usos del pasado histórico nacional tienden por lo tanto a forjar una ilusoria verdad histórica que rompe por lo tanto con el método crítico y los criterios de interpretación propios de las ciencias sociales: es memoria alternativa la que se impulsa desde los canales de la historia oficial, dentro de esas religiones republicanas asentadas en el desencanto. En ese aspecto, las conmemoraciones del Bicentenario en el transcurso del año 2011 no hicieron sino acentuar y evidenciar al mismo tiempo el propósito de presidente y de sus seguidores de asentar la nueva historia oficial en un culto fundacional retocado, elemento 
entre otros ahora de la extrema polarización de la opinión pública en una democracia formal. Mientras en otras partes del continente los usos del pasado reciente y la imprescindible confrontación entre historia oficial y memoria colectiva acompañan la democratización de la sociedad, la defensa de los derechos humanos el reconocimiento de una cultura política pluralista, y que en la relación simbólica a la historia se originan distintos regímenes de historicidad a la par que se va edificando una memoria por definición inconclusa y sentando por lo tanto una “cultura de la memoria”, la contienda bolivarianista sólo pone de manifiesto el enfrentamiento entre dos concepciones de la libertad. De la historia concebida como creencia se deriva la imposición de una historia oficial cuyos actores, pese a ser a veces historiadores de oficio, no dejan de ser defensores de la nueva religión cívica en la cual el pueblo es “bueno” y la política “mala” (planteamiento frecuente en los regímenes de inspiración populista). Si bien resulta legítimo construir una memoria y abrir un debate público incluyendo propuestas diversas incluyendo las del poder político de turno, y que los historiadores no tienen un monopolio del pasado, lo que sí resulta problemático es el uso univoco y orientado que se le quiere dar al pasado histórico. Como lo subrayó Hilda Sabato en el caso de Argentina, "hay un uso del pasado que no contribuye a generar una sociedad más pluralista, mas democrática, más amplia, sino todo lo contrario: refuerza los estereotipos y las visiones dicotómicas” (Pino Iturrieta, $2003^{a}$; Capdevila y Langue, 2009; Langue, 2010; Allier Montaño, 2010; Stern, 2010: 273, 297; Carpena, 2011) ${ }^{16}$.

La historia reciente, con la actualidad del Bicentenario y la promoción del desvirtuado “culto a Bolívar”, junto a la escasa tolerancia propia del personalismo político de hoy, muestra que la nueva religión cívica bolivariana privilegia símbolos y rituales resguardados en un panteón cuyos referentes, pese a las apariencias inmediatas, pertenecen más al pasado lejano que al presente, y son productos de la manipulación de la historia más de la mirada crítica del historiador de oficio. El último episodio de lo que podemos considerar como la lucha por la memoria del Libertador se inició e efecto con motivo de la divulgación del archivo del Libertador en Internet. El enfrentamiento se da ahora entre los instituciones, la Academia Nacional de la Historia (ANH) y el Archivo General de la Nación (AGN), a través de sitios web que ambas instituciones establecieron -la Academia, el Instituto de Investigaciones Históricas de la Universidad Simón Bolívar y la Escuela de Bibliotecología y Archivología de la Universidad Central de Venezuela a partir del 20 de junio, y el Archivo en julio (como parte de la conmemoración del Bicentenario de la Independencia)- para divulgar precisamente los documentos originales de Bolívar (Paullier, 2011) ${ }^{17}$. No se busca alcanzar una "memoria justa” como es el caso de los países del Cono Sur, contraponiéndola a los crímenes de la dictadura y en todo caso a un pasado conflictivo y al recuerdo de regímenes autoritarios, sino se remonta a un siglo XIX guerrero y heroicizado. El historicismo político bolivariano en su versión actual busca borrar el itinerario democrático de la nación para construir una sociedad “distinta” (socialista) en la que no se trata para nada de “vivir juntos” (la argumentación la funda el resentimien- 
to), y en todo caso una memoria manipulada y única del pasado nacional: según E. Pino, H. Chávez plantea en efecto en la obra de Bolívar un "pensamiento precursor del socialismo del siglo XXI» (Vezzetti, 2010: 81-95).

La ausencia del mandatario venezolano en junio de 2011 y su oportuno y simbólico regreso desde Cuba en vísperas del 5 de julio (Bicentenario de la Independencia de Venezuela) apunta además a la fuerte personalización del quehacer político en Venezuela y a la realidad de un liderazgo mesiánico ahora contrastado tanto a nivel nacional como continental. Más allá de un realismo mágico arraigado en las vivencias criollas y hasta de la sensación de brujería vinculada con la exhumación de los restos de Bolívar y las últimas declaraciones presidenciales al respecto con motivo de las fiestas del Bicentenario (reiterando la teoría del asesinato que mencionamos anteriormente), Venezuela se enfrenta ahora con una abierta guerra de las memorias junto a una persistente dramatización del mito bolivariano. El manejo e incluso las falsificaciones del culto fundacional o mejor dicho de la "religión republicana” abarca distintos escenarios mediatizados de forma sistemática: de la vida política y sus arengas y consignas lanzadas desde el "balcón del pueblo”, a la divulgación y enseñanza de la historia, incluyendo esa peculiar reescritura de la historia para mencionar tan sólo los aspectos con mayores implicaciones en términos discursivos y comunicacionales) (Welsch, 2007; Ochoa Antich, 2011; Salas de Lecuna, 2004: 91-109 y 2000).

El caso de la Venezuela bolivariana constituye en este sentido una ilustración más de la contradicción fundamental — tal como la señaló P. Ricœur - entre la labor unificadora y pacificadora de la historia y la división se origina en memorias enfrentadas y hasta competidoras. También podríamos mencionar en este sentido el desgaste de los modelos y conceptos historiográficos vigentes (desde la perspectiva de una historiografía colectiva), la persistencia de "relatos invariables" acerca de procesos clave de la historia nacional (i.e.: emancipación e independencia) y la consiguiente necesidad de una reflexión crítica y extralimitada - más allá de los límites cronológicos y espaciales de los eventos reinterpretados — sobre el particular (Quintero, 2011; Pino Iturrieta, 2011). Ahora bien, estas memorias laberínticas reivindicadas desde el poder político y promovidas por el "verbo incendiario" del presidente en contra de contradictores convertidos en "enemigos", las mueve no el conocimiento de la historia en cuanto ciencia social, sino ambiciones "simplificadoras" junto a creencias y emociones que incorporan pasiones propias de la teleología de turno. Esta "construcción de subjetividades nacionales en situación de conflicto” las acentúa además contiendas ideologizadas arraigadas en el pasado y en sus “estatuas”. Estas no constituyen además ninguna novedad ya que nutrieron los dilemas intelectuales y políticos de los primeros republicanos de Hispanoamérica, el devenir de las naciones imaginadas nacidas de las revoluciones de Independencia. Hoy en día, no dejan de “inspirar” la reflexión acerca del imprescindible "papel social” del historiador confrontado con los usos políticos del pasado que convierten al pro- 
Polis, Revista Latinoamericana, Volumen 12, No 34, 2013

ceso de Independencia en una "divina Independencia” y una Independencia "a palos", y a la figura del Libertador en evangelio (Pino Iturrieta, 2010 a y b, 2011: 16, 26, 171-173; Anderson, 1993; Castro Leiva, 1991: 117151, 205, Hartog-Revel, 2001). 


\section{Notas}

${ }^{1}$ Una declaración en este sentido: R. Baduel alude a una "dictadura con ropaje democrático”. “¿Un dictador sensible?”, Tal Cual, 29 de julio de 2011. http://vene-cuba.blogspot.fr/ 2011/07/un-dictador-sensible.html Consultado el 30 de mayo de 2012.

${ }^{2}$ Reporteros Sin Fronteras, 2010. http://www.rsf-es.org/news/venezuela-nuevas-leyes-queamenazan-las-libertades/ Consultado el 29 de mayo de 2012.

${ }^{3}$ Véanse sobre el particular los reportajes en los diarios El Universal, El Nacional o Tal Cual.

${ }^{4}$ Término utilizado por los partidarios del Presidente Chávez.

${ }^{5}$ BBC Mundo: "Simón Bolívar no habría sido asesinado”, 25 de julio de 2011 http:// w w w. b b c . c o. u k/m und o/ u l t i mas_notici a s/2011/0 7 / 110725_ultnot_bolivar_informe_cch.shtml Ministerio Popular para la Ciencia, Tecnología e Industrias Intermedias http://www.cida.gob.ve/cida_home/ index.php?option=com_content\&view=article \&id=557:4-de-febrero-dia-de-ladignidad\&catid=108: noticias-comunidad\&Itemid=71 Otros sitios oficiales: http:// www.minci.gob.ve/doc/4feb2011xixaniversariod.doc , www.venezuelaencuba.co.cu/.../2011/ 02\%20Febrero/.../11020401.html y: http://ameliach.psuv.org.ve/2011/02/04/tema/noticias/ 4f-rescato-dignidad-nacional/

BBC Mundo, 30 de julio de 2011 http://www.bbc.co.uk/mundo/noticias/2011/07/ 110730_chavez_autocritica_socialismo_rg.shtml?print $=1$

${ }^{6}$ Presidente electo en diciembre de 1998, confortado por medio del referéndum sobre la Constitución Bolivariana (1999), Hugo Chávez fue elegido nuevamente en 2000 y 2006. Una revisión exhaustiva de esta década en el poder puede leerse en la obra colectiva de Ramos Pismataro, F., Romero, C. A., Ramírez Arcos, H.E. (eds.), 2010.

${ }^{7}$ Aristócrata criollo blanco en Venezuela colonial.

${ }^{9}$ Centro Nacional de Historia http://www.cnh.gob.ve/ Presentación del sitio y Memorias de Venezuela, ene-feb 2008 n $^{\circ}$ 1. Consultado el 30 de mayo de 2012.

${ }^{10}$ Ibídem.

${ }^{11} \mathrm{CNH}$ Memorias de Venezuela, 1, 2008. http://www.cnh.gob.ve/

12 Vídeo de la exhumación de los restos del Libertador en Youtube (18/7/2010, puesto en línea por misionchavezcandanga), http:/www.youtube.com/watch?v=j3f7OpT2168 y "Exhumación de Simón Bolívar 1/3 Presidente Hugo Chávez lo muestra. Venezuela” (17/7/ 2010), http://www.youtube.com/watch?v=DEnihniqTLc\&feature=related

${ }^{13}$ Comunicado de la Academia Nacional de la Historia con fecha del 30 de julio de 2010. http://www.anhvenezuela.org/

14
index.php?option=com_docman\&task=cat_view\&gid=21\&Itemid=44


Polis, Revista Latinoamericana, Volumen 12, $N^{\circ}$ 34, 2013

${ }^{15}$ El Universal y El Nacional, 6 de julio, 2010. Entrevista con Germán Carrera Damas, El Universal, 12 de mayo de 2010.

${ }^{16}$ The Economist, 11 de julio, 2010.

${ }^{17}$ Academia Nacional de la Historia http://www.anhvenezuela.org/ y AGN http:// www.agn.gob.ve/ 


\section{Bibliografía}

Allier Montaño Eugenia (2010), Batallas por la memoria. Los usos politicos del pasado reciente en Uruguay, Ed Trilce-UNAM (IIS), México.

Almarza, Angel Rafael (2011), “Dos siglos de historias mal contadas”, en Quintero, I. (coord), El relato invariable, Ed. Alfa, 125-154, Caracas.

Althusser, Louis (1976), “Idéologie et appareils idéologiques d’Etat”, en Positions, Les Éditions Sociales, Paris. En: http://classiques.uqac.ca/ contemporains/althusser_louis/althusser_louis.html Consultado el 30 de mayo de 2012.

Anderson, Benedict (1993), Comunidades Imaginadas, FCE, Buenos Aires (1ra ed. Londres, 1983).

Aponte Blank, Carlos, Gómez Calcaño, Luis (2009), “El régimen político en la Venezuela actual”, en IDLIS, febrero de 2009. En: http:// www.ildis.org.ve/website/p_index.php?ids=7\&tipo=P\&vermas=146 Consultado el 30 de mayo de 2012.

Arenas, Nelly (2007), "Poder reconcentrado: el populismo autoritario de Hugo Chávez” en Politeia, 39, (2007): 23-63. En: http:// www2.scielo.org.ve/pdf/poli/v30n39/art02.pdf Consultado el 30 de mayo de 2012.

Austin, John L. (1962), How to do Things with Words, Clarendon, Oxford. En: http://www.dwrl.utexas.edu/ davis/crs/rhe321/Austin-How-To-DoThings.pdf Consultado el 30 de mayo de 2012.

Arenas, Nelly, Gómez Calcaño, Luis (2000), “El imaginario redentor: de la Revolución de Octubre a la Quinta República Bolivariana” [en línea]. Temas para la discusión (CENDES-UCV) 6, 2000. En: http://www.nuso.org/ upload/articulos/3295_1.pdf Consultado el 30 de mayo de 2012.

Arenas, Nelly y Gómez Calcaño, Luis (2004), "Los círculos bolivarianos. El mito de la unidad del pueblo”, en Revista Venezolana De Ciencia Política, n $^{\circ 25}$, 5-37. En: http://redalyc.uaemex.mx/pdf/308/30803907.pdf Consultado el 30 de mayo de 2012.

Bourdieu, Pierre (1982), Ce que parler veut dire: l'économie des échanges linguistiques, Fayard, París.

Braud, Philippe (1993), “La violence politique: repères et problèmes”, en Cultures \& Conflits, n09-10. En: http://conflits.revues.org/index406.html Consultado el 30 de mayo de 2012.

Buttó, Luis Alberto (2010, “Diez años de Revolución Bolivariana: impacto en las relaciones civiles y militares”, en Ramos Pismataro, F. Romero, 
C. A., Ramírez Arcos, H. E. (Eds.), Hugo Chávez: una década en el poder, Universidad del Rosario/Centro de Estudios Políticos e Internacionales/ Observatorio de Venezuela, 783-800, Bogotá,.

Caballero, Manuel (1994), Gómez, el tirano. Liberal, Monte Avila, Caracas.

Caballero, Manuel (1998), Las crisis de la Venezuela contemporánea, Monte Avila, Caracas.

Capdevila, Luc, Langue, Frédérique (Coords., 2009), Entre mémoire collective et histoire officielle. L'histoire du temps présent en Amérique latine, Presses Universitaires de Rennes, Rennes.

Capriles, Ruth (2008), El libro rojo del resentimiento, Debate, Caracas.

Carpena, Ricardo (2011), «Hay un uso del pasado que refuerza los estereotipos» Entrevista con Hilda Sabato, La Nación, 31 de julio. En: http:// www.lanacion.com.ar/1393415-hay-un-uso-del-pasado-que-refuerza-losestereotipos Consultado el 30 de mayo de 2012.

Carrera Damas, Germán (1989), El culto a Bolívar, Grijalbo, Caracas.

Carrera Damas, Germán (2001), Alternativas ideológicas en América Latina contemporánea (El caso de Venezuela: el bolivarianismo-militarismo), University of Florida-Universidad Central de Venezuela, Gainesville.

Carrera Damas, Germán (2007), “Entre el héroe nacional-padre de la Patria y el anti-héroe nacional-padrote de la patria”, en Arbor Ciencia-Pensamiento y cultura, ${ }^{\circ}$ CLXXXIII-724, Madrid, 203-210. En: http:// www.saber.ula.ve/db/ssaber/Edocs/pubelectronicas/procesoshistoricos/ vol5num10/documento1.pdf Consultado el 30 de mayo de 2012.

Castillo, H., Irwin, D., Langue, F. (2009), Problemas Militares Venezolanos. FANB y Democracia en los inicios del siglo XXI, Universidad Pedagógica Experimental Libertador y Universidad Católica Andrés Bello, Caracas.

Castro Leiva, Luis (1991), De la patria boba a la teología bolivariana, Monte Avila, Caracas.

Coronil, Fernando (2002), El Estado mágico. Naturaleza, dinero y modernidad en Venezuela, Ed. Nueva Sociedad, Caracas (1997, University of Chicago Press).

Dieterich, Heinz (2004), Hugo Chávez: el destino superior de los pueblos latinoamericanos: conversaciones con Heinz Dieterich, Alcaldía de Caracas, Caracas. 
Eribon, Didier (1982), “ 'Ce que parler veut dire'. Entretien de Didier Éribon”( Entrevista con P. Bourdieu), en Libération, 19 de octubre. En: http://adonnart.free.fr/doc/parler.htm Consultado el 30 de mayo de 2012.

Farge, Arlette (2002), "Penser et définir l’événement en histoire. Approche des situations et des acteurs sociaux”, en Terrains, n³8, 69-78. En: http:/ /terrain.revues.org/1929 Consultado el 30 de mayo de 2012.

Ferro, Marc (2007), Le ressentiment dans l'histoire, Odile Jacob, París.

Franco, Marina (2012), Un enemigo para la nación. Orden interno, violencia y “subversión”, 1973-1976, FCE, Buenos Aires.

García Larralde, Humberto (2007), “Pueblo y populismo en el imaginario de Hugo Chávez”. Simposio Populismo, Goethe-Institut Venezuela 2007. En: http://www.goethe.de/ins/ve/prj/eld/sy2/esindex.htm Consultado el 30 de mayo de 2012.

Gómez, Alejandro (2005), “La reliquia más preciada de la Revolución bolivariana”, en Domingo Irwin G., Frédérique Langue (coord.), Militares y poder en Venezuela. Ensayos históricos vinculados con las relaciones civiles y militares venezolanas, UPEL-UCAB, 179-203, Caracas.

González Deluca, María Elena (2005), “Historia, usos, mitos, demonios y magia revolucionaria”, 2005, en Revista Venezolana de Economía y Ciencias Sociales. $N^{\circ} 11-2,159-186$. En: http://www.scielo.org.ve/ scielo.php?pid=S1315-64112005000200008\&script=sci_arttext Consultado el 30 de mayo de 2012.

González, José María Salvador (2007), “Escenario y figura de Bolívar Super-Héroe en la Venezuela de 1870-1899”, en Espéculo. Revista de estudios literarios, n³5. En: http://www.ucm.es/info/especulo/numero35/ bolivars.html Consultado el 30 de mayo de 2012.

Guardia Rolando, Inés, y Guerrero Álvarez Larissa (2010), “Violencia política e inseguridad en Venezuela (1998-2008)”, en Ramos Pismataro, F. Romero, C. A., Ramírez Arcos, H. E. (Eds.), Hugo Chávez: una década en el poder, Universidad del Rosario/Centro de Estudios Políticos e Internacionales/Observatorio de Venezuela, 305-321, Bogotá.

Guardia Rolando, Inés, y Olivieri Giannina (2003), “El ciudadano en armas: Círculos Bolivarianos y planes de contingencia. Una explicación de la violencia política actual en Venezuela”, L’Ordinaire latino-américain, n¹92, Université de Toulouse-Le Mirail, 85-107.

Guerra, José (2008), “La ambición de poder de Juan Vicente Gómez y Hugo Chávez”, Noticias 24, 9 de diciembre. En: http://www.noticias24.com/ actualidad/noticia/21232/la-ambicion-de-poder-de-juan-vicente-gomez-yhugo-chavez/ Consultado el 30 de mayo de 2012. 
Guilhaumou, Jacques, Maldidier, Denise, Prost, Antoine, Robin, Régine (1974), Langage et idéologies. Le Discours comme objet de l'Histoire, Les Editions ouvrières, París. En: http://gallica.bnf.fr/ark:/12148/ bpt6k5710023z/f4.image Consultado el 30 de mayo de 2012.

Hartog, François, Revel, Jacques (dir., 2001), Les usages politiques du passé, Editions de l’Ecole des Hautes Etudes en Sciences Sociales, París.

Hernández, Ana María (2010), “Entrevista con Germán Carrera Damas”, El Universal, 12 de julio. En: http://venezuelaysuhistoria.blogspot.com/ 2010/05/historiador-venezolano-german-carrera.html Consultado el 30 de mayo de 2012.

Irwin, Domingo (2010), "Relaciones civiles y militares en Venezuela (19982008)”, en Ramos Pismataro, F. Romero, C. A., Ramírez Arcos, H. E. (Eds.), Hugo Chávez: una década en el poder, Universidad del Rosario/Centro de Estudios Políticos e Internacionales/Observatorio de Venezuela, 743-760, Bogotá.

Irwin, Domingo, y Buttó, Luis Alberto (2006), “ ‘Bolivarianismos’ y Fuerza Armada en Venezuela. Los bolivarianismos en la mirada de las ciencias sociales”, en Nuevo Mundo Mundos Nuevos, n6. En: http://nuevomundo.revues.org/ document1320.html Consultado el 30 de mayo de 2012.

Irwin, Domingo, y Langue, Frédérique (2004), «Militares y democracia ¿El dilema de la Venezuela de principios del siglo XXI?», en Revista de Indias, $\mathrm{n}^{\circ} 231$, 549-559. En: http://revistadeindias.revistas.csic.es/ index.php/revistadeindias Consultado el 30 de mayo de 2012.

Jácome, Francine (2008), “¿Renovación/resurgimiento del populismo? El caso de Venezuela y sus impactos regionales”. Proyecto Nueva Agenda de Cohesión Social para América Latina, IFHC-Instituto Fernando Henrique Cardoso (Sao Paulo)-CIEPLAN-Corporación de Estudios para Latinoamérica (Santiago, Chile). En: http://plataformademocratica.org Consultado el 30 de mayo de 2012.

Kerbrat-Orecchioni, Catherine (2008), Les actes de langage dans le discours. Théorie et fonctionnement, Nathan, París.

Laborie, Pierre (2001), L'opinion française sous Vichy. Les Français et la crise d'identité nationale, 1936-1944, Le Seuil, París.

Langue, Frédérique (2002), Hugo Chávez. Une action politique au pays de Bolívar, L’Harmattan, París.

Ídem (2009a), “¿Encanto populista o revolución continental? El proyecto bolivariano de Hugo Chávez entre dos siglos”. En Hermosa Andujar, A., Schmidt, S. (Eds.), Pensar Iberoamérica, Prometeo Libros, Buenos Aires, 95-136. 
Ídem (2009b), “Rómulo Betancourt. Liderazgo democrático versus personalismo en tiempos de celebraciones”, Araucaria Revista Iberoamericana de Filosofía, Política y Humanidades, n²1, 226-238. En: http:// www.institucional.us.es/araucaria/nro21/nro21.htm Consultado el 30 de mayo de 2012.

Ídem (2009c), “La Independencia de Venezuela. Una historia mitificada y un paradigma heroico", Anuario de Estudios Americanos, n66-2, Sevilla, 245-276. En: http://estudiosamericanos.revistas.csic.es/index.php/ estudiosamericanos/article/view/324 Consultado el 30 de mayo de 2012.

Ídem (2010), “De panteones cívicos e imaginarios políticos. Los usos del pasado en la Revolución bolivariana”, En Hugo Chávez: una década en el poder, Ramos Pismataro, F. Romero, C. A., Ramírez Arcos, H. E. (eds.), Universidad del Rosario/Centro de Estudios Políticos e Internacionales/ Observatorio de Venezuela, 761-781, Bogotá.

Ídem (2011), “ ‘Levántate Simón, que no es tiempo de morir’. Reinvención del Libertador e historia oficial en Venezuela”, Araucaria Revista Iberoamericana de Filosofía, Política y Humanidades, n²5. En: http://wwwen.us.es/araucaria/nro25/nro25.htm Consultado el 30 de mayo de 2012.

Lombardi, Angel Rafael (2010), “La rebelión de los historiadores”, Tal Cual, 22 de julio. En: http://www.analitica.com/va/politica/opinion/ 7410587.asp. Consultado el 30 de mayo de 2012.

López Maya, Margarita y Lander, Luis E. (2006), “Popular Protest in Venezuela: Novelties and Continuities”, en Hank, J., y Almeida, P. (Eds.), Latin American Social Movements: Globalization, Democratization, and Transnacional Networks, Anham, Rowman \& Littlefield Publishes, 43-56, New York.

Lynch, John (2007), Simón Bolívar. A Life, Yale University Press, New Haven-London.

Mares, David. R. (2001), Militarized Interstate Bargainning in Latin America, Columbia University Press, New York.

Narvaja de Arnoux, Elvira (2008), El discurso latinoamericanista de Hugo Chávez, Ed. Biblios, Buenos Aires.

Navet, Georges y Vermeren, Patrice (2003), “Théories de la violence, politiques de la mémoire et sujets de la démocratie”. Topique, ${ }^{\circ} 83$, París, 43-53. En: http://www.cairn.info/revue-topique-2003-2-page-43.htm Consultado el 30 de mayo de 2012.

Ochoa Antich, Enrique (2011), “Autocracia, superstitición y muerte ”, Tal Cual 1 de agosto, 2011. En: http://www.talcualdigital.com/Avances/Viewe r.aspx?id=56345\&orig=RSS\&secID=44 Consultado el 30 de mayo de 2012. 
Paullier, Juan (2011), “Con polémica, el archivo de Bolívar llega a Internet”. BBC Mundo, 16 de junio. En: http://www.bbc.co.uk/mundo/noticias/2011/ 06/110616_venezuela_archivo_simon_bolivar_internet_jp.shtml?print=1 Consultado el 30 de mayo de 2012.

Peñaloza, Carlos (2011), “ ‘Patria o Muerte’, el lema ilegal”, Venezuela analítica, 17 de julio. En: http://www.analitica.com/va/politica/opinion/ 5406803.asp Consultado el 30 de mayo de 2012.

Pino Iturrieta, Elías (2003ª), El divino Bolívar. Ensayo sobre una religión republicana, Ed. de la Catarata, Madrid.

Ídem (2003b), “La historia oficial”, El Universal, 27 de noviembre. En: http://www.eluniversal.com/ Consultado el 30 de mayo de 2012.

Ídem (2007 $)$, Nada sino un hombre. Los orígenes del personalismo en Venezuela, Editorial Alfa, Caracas.

Ídem (2007b), “Los mitos políticos se gastan”, Tal Cual Digital. 1 de noviembre. En: http://espanol.groups.yahoo.com/group/UPLA-VEN_Ccs/ message/43504 Consultado el 30 de mayo de 2012.

Ídem (2010ª), “Chávez y Bolívar”, El Universal, 24 de julio. En: http:// www.eluniversal.com/2010/07/24/opi_art_gomez, -chavez-yboli_1977513.shtml Consultado el 30 de mayo de 2012.

Ídem (2010b), “La guerra de la memoria”, El Universal, 26 de septiembre. En: http://www.noticierodigital.com/forum/ viewtopic.php?t=578631\&view=next\&sid=705f71de9d900f4efcfeee5770074da5 Consultado el 30 de mayo de 2012.

Ídem (2010c), “La traición a la patria”, El Universal, 28 de agosto. En: http://www.noticierodigital.com/2010/08/la-traicion-a-la-patria/ Consultado el 30 de mayo de 2012 .

Ídem (2011), La Independencia a palos, Editorial Alfa, Caracas.

Plaza, Elena (2001), “La idea del gobernante fuerte en la historia de Venezuela (1819-1999)” . Politeia, n²7, Caracas, 7-24. En: http:// www2.scielo.org.ve/scielo.php?script=sci_abstract\&pid=S030397572001000200001\&lng=es\&nrm=iso Consultado el 30 de mayo de 2012.

Pratt, Mary Louise (2011), “Thinking Through Violence. Violence and Language”, en Social Text, May 21, Columbia University. En: http:// www.socialtextjournal.org/periscope/2011/05/violence-and-languagemary-louise-pratt.php Consultado el 30 de mayo de 2012.

Quintero, Inés (Coord., 2011), El relato invariable. Independencia, mito y nación, Editorial Alfa, Caracas. 
Ramos Jiménez, Alfredo (2002), “Chávez en el poder. Notas sobre la transición venezolana”, Reflexión política, n4-7, Bucaramanga, 2-13. En: http:/ /redalyc.uaemex.mx/redalyc/pdf/110/11040703.pdf Consultado el 30 de mayo de 2012.

Ramos Jiménez, Alfredo (2009), El experimento bolivariano. Liderazgo, partidos y elecciones, Universidad de los Andres/CIPCOM, Mérida.

Ramos Pismataro, F., Romero, C. A., Ramírez Arcos, H. E., comps. (2010), Hugo Chávez: una década en el poder, Universidad del Rosario/Centro de Estudios Políticos e Internacionales/Observatorio de Venezuela, Bogotá.

Rangel, Carlos (2007), Del buen salvaje al buen revolucionario. Mitos y realidades de América Latina, Gota-Fundación FAES, Madrid.

Rey, Juan Carlos (1991), “La democracia venezolana y la crisis del sistema populista de conciliación”, en Revista de estudios políticos, n74, Caracas, 533-578. En: http://dialnet.unirioja.es/servlet/articulo?codigo=27121 Consultado el 30 de mayo de 2012.

Rico, Maite (2010), “La reinvención del Libertador”, en El País, 17 de julio. En: http://www.elpais.com//articulo/internacional/reinvencion/Libertador/elpepiint/20100717elpepiint_2/Tes Consultado el 30 de mayo de 2012.

Ricœur, Paul (2000), La mémoire, l’histoire, l’oubli, Seuil, París (trad. 2004: La memoria, la historia, el olvido, FCE, México).

Rojas, Reinaldo (2011), Venezuela: Fiesta, imaginario político y nación, UNEY, San Felipe, Venezuela.

Salas de Lecuna, Yolanda (1987), Bolívar en la historia en la conciencia popular, Ed. Universidad Simón Bolívar, Caracas.

Ídem (2004), “ La “ Revolución Bolivariana ” y la “ sociedad civil ”: la construcción de subjetividades nacionales en situación de conflicto ”, en Revista Venezolana de Economía y Ciencias Sociales, $\mathrm{n}^{\circ} 10-2$, Caracas, 91-109. Disponible en Redalyc: http://www.redalyc.uaemex.mx/pdf/177/ 17710207.pdf Consultado el 29 de mayo de 2012.

Ídem (2005), "La dramatización social y política del imaginario popular: el fenómeno del bolivarismo en Venezuela”, en Cultura, política y sociedad Perspectivas latinoamericanas, Mato, Daniel (comp.), CLACSO, Buenos Aires, 241-263. En: http://bibliotecavirtual.clacso.org.ar/ar/libros/ grupos/mato/Salas.rtf Consultado el 30 de mayo de 2012.

Searl, John (1972), Les actes de langage, Hermann, París.

Soriano de García Pelayo, Graciela (1996), El personalismo político his- 
panoamericano. del siglo XIX, Monte Avila, Caracas.

Stern, Steve J. (2010), Reckoning with Pinochet. The Memory Question in Democratic Chile, 1989-2006, Duke University Press.

Straka, Tomás (2009ª $)$ La épica del desencanto. Bolivarianismo, Historiografía y Política en Venezuela, Editorial Alfa, Caracas.

Ídem (2009b), `¿Hartos de Bolívar? La rebelión de los historiadores contra el culto fundacional ", en Boletín de la Academia Nacional de la Historia, n³65, Caracas, 51-91.

Torre, Carlos de la (2000), Populist seduction in Latin America. The Ecuadorian Experience, Ohio University Press.

Torres, Ana Teresa (2009), La herencia de la tribu. Del mito de la Independencia a la Revolución Bolivariana., Editorial Alfa, Caracas.

Uzcátegui, José Luis (1999), Chávez, mago de las emociones. Análisis psicosocial de un fenómeno político, Lithopolar Gráficas, Caracas.

Vezzetti, Hugo (2010), “La memoria justa: política e historia en la Argentina del presente”, en Problemas de historia reciente del Cono Sur, Vol. I, Boholavsky E., Franco M., Iglesias, M., Llovich D. (comps.), Universidad Nacional de General Sarmiento-Prometeo Libros, 81-95, Buenos Aires.

Welsch, Friedrich 2007), "Populismo y cultura política, en perspectiva comparada”, en Simposio Populismo, Goethe-Institut Venezuela. En: http:/ /www.goethe.de/ins/ve/prj/eld/sy2/esindex.htm Consultado el 30 de mayo de 2012.

Zago, Angela (1998), La rebelión de los ángeles. Reportaje. Los documentos del movimiento, Warp Ediciones, Caracas.

Recibido : 19.12.2012

Aceptado :09.01.2013 